\title{
Emerging new biomarkers in obstructive sleep apnea
}

\author{
Shailendra Kapoor
}

Received: 6 October 2012 / Accepted: 22 October 2012 / Published online: 1 November 2012

(C) Springer-Verlag Berlin Heidelberg 2012

\section{Dear Editor,}

The recent article by Wang et al. was highly interesting and thought provoking [1]. Interestingly, the past few years have seen the identification of novel new biomarkers of obstructive sleep apnea (OSA).

For instance, accentuated levels of the plasma adhesion molecules vascular cell adhesion molecule 1 (VCAM-1) and intercellular adhesion molecule 1 (ICAM-1) are seen in patients with OSA. A close positive relationship has been noted between elevated levels of VCAM-1 and the apneahypopnea index [2]. A similar relationship exists between ICAM-1 and the oxygen desaturation index. A similar positive relationship exists between VCAM-1 and ICAM-1 and the apnea-hypopnea index.

In addition, E-selectin is elevated in patients with OSA. In fact, E-selectin is an independent indicator of accentuated atherogenesis in patients with OSA [3]. Similarly, higher P-selectin levels are an indicator of more severe OSA. Some studies have shown a similar association between L-selectin and OSA while others have shown no association $[2,4]$.

Another relatively new marker is plasma thioredoxin. The effectiveness of continuous positive airway pressure (CPAP) in individuals with OSA can be closely monitored by measuring the plasma thioredoxin levels [5]. Hepcidin is another new emerging prognostic marker for obstructive sleep apnea [6]. Similarly, a positive association exists between the apnea-hypopnea index and the morning exhaled 8 -isoprostane levels. 8-Isoprostane is reduced following

S. Kapoor $(\square)$

Mechanicsville, VA, USA

e-mail: shailendrakapoor@yahoo.com
CPAP therapy and serves as an indicator of effectiveness of CPAP therapy [7].

The above examples illustrate the importance of these markers in OSA and the need to increase awareness among physicians about these markers.

Conflict of interest The author has no conflict of interest to declare.

\section{References}

1. Wang Y, Li Y, Chen P, Luo Y, Yang Y, Yang Y (2012) Elevated fractalkine in patients with obstructive sleep apnea hypopnea syndrome. Sleep Breath. doi:10.1007/s11325-012-0674-6

2. El-Solh AA, Mador MJ, Sikka P, Dhillon RS, Amsterdam D, Grant BJ (2002) Adhesion molecules in patients with coronary artery disease and moderate-to-severe obstructive sleep apnea. Chest 121 (5):1541-1547

3. Cofta S, Wysocka E, Michalak S, Piorunek T, Batura-Gabryel H, Torlinski L (2009) Endothelium-derived markers and antioxidant status in the blood of obstructive sleep apnea males. Eur J Med Res 14(Suppl 4):49-52

4. Cofta S, Wysocka E, Dziegielewska-Gesiak S, Michalak S, Piorunek T, Batura-Gabryel H, Torlinski L (2013) Plasma selectins in patients with obstructive sleep apnea. Adv Exp Med Bio 756:113-119

5. Takahashi K, Chin K, Nakamura H, Morita S, Sumi K, Oga T, Matsumoto H, Niimi A, Fukuhara S, Yodoi J, Mishima M (2008) Plasma thioredoxin, a novel oxidative stress marker, in patients with obstructive sleep apnea before and after nasal continuous positive airway pressure. Antioxid Redox Signal 10(4):715-726

6. Kanbay A, Hasanoglu HC (2007) A new prognostic marker for obstructive sleep apnea: hepcidin. Med Hypotheses 69(6):1381-1382

7. Anonymous (2003) 8-Isoprostane, a marker of oxidative stress, is increased in exhaled breath condensate of patients with obstructive sleep apnea after night and is reduced by continuous positive airway pressure therapy. Chest 124(4):1386-1392 